\title{
Quality issues of herbal medicines: internal and external factors
}

\section{Opinion}

Herbal medicines are the most ancient form of health remedies known to humankind. Despite the great advances achieved in modern medicine, plants still make an important contribution to health care, and several specific herbal extracts have been demonstrated to be efficacious for specific conditions. Moreover, at least 120 distinct chemical substances derived from plants are considered important drugs currently in use, and several other drugs are simple synthetic modifications of natural products. ${ }^{1}$ In reality, it must also be stated that certain tightly held beliefs within traditional medicine have created an environment where strong belief "counts" more than the application of scientific principles. ${ }^{2}$ Plants can be regarded as "living factories" producing a variety of chemical compounds, including primary metabolites important for the growth of the plants (amino acids, proteins, carbohydrates) and secondary metabolites (alkaloids, terpenoids, phenylpropanoids, polyketides, flavonoids, saccharides). All these components may work together to deliver a synergistic effect in the finished product.

Certain herbal medicines, because of the complexity of their chemical content and the variety of bioactivities, can provide the polypharmacology that orthodox drugs cannot deliver. Natural products are rarely evaluated in the well-controlled clinical trials that are required to receive approval by regulatory bodies; therefore, they tend to have less scientific evidence to support their efficacy. However, all medicinal compounds are chemicals, whether synthesized in plants, animals, or in manufacturing laboratories, therefore, all medicinal chemical compounds should be held accountable to similar standards of quality (identity, purity, and stability), clinical effectiveness and safety; irrespective of their source, "If it is found to be reasonably safe and effective, it will be accepted"3 Reliable and consistent quality is the basis of efficacy and safety of herbal medicinal products. Given the nature of products of plant origin, which are highly variable and complex products with numerous biologically active components rarely completely identified, therapeutic results and safety issues vary greatly from product to product, even within a single class. Therefore, the evidence of both benefits and risks is specific to the product tested and cannot necessarily be extrapolated to other products, as is the case for synthetically derived compounds.

For these reasons, and due to the inherent variability of the constituents of herbal products, it is generally difficult to establish quality control parameter and maintain consistent batch-tobatch quality; variation in the absence of reference standards for identification can start from the collection of raw materials and increase during storage and further processing.

\section{Genesis}

"The use of traditional medicines, phytotherapeuticals, and dietary supplements should be based on quality, safety, efficacy, and consistency (QSEC)". ${ }^{2}$ Traditional medicine was the only form of drugbased healing system in many parts of the world prior to introduction of aspirin in 1899. Over time, more than 50,000 biologically active plants have been described around the world (IUCN, 2007, https://
Volume II Issue I - 2018

\author{
Dilip Ghosh \\ Director, Nutriconnect, Australia
}

Correspondence: Dilip Ghosh, Director, Nutriconnect, SFI Asia Pacific, Level 2, 170 Pacific Highway, St Leonards, NSW 2065, Australia, Tel +6I 2943 I 72I2, Fax +6I (2) 943I 7272, Email dghosh@optusnet.com.au, dilipghosh@nutriconnect.com.au

Received: August 0I, 2017 | Published: February 12, 2018

www.iucn.org/theme/species/our-work/plants, accessed on 22 December 2017). The World Health Organization has recognized this need for an evidence base for all aspects of traditional medicine, making it clear in documents for many years $(2002-2005,2012)$ that the introduction of traditional medicine (TM) into healthcare systems must be based on evidence of QSEC. The food/dietary supplements and herbal medicine products that are ingested are becoming a subject of increasing scrutiny and surveillance. Nowadays, the official regulatory agencies such as Food and Drug Administration (FDA), European Medicines Agency (EMA), European Food Safety Authority (EFSA), Therapeutic Goods Administration (TGA), Health Canada and so on ask industry for development of the food quality assurance program. In the past, there was not a widespread focus on the quality and safety of ingested health supplements. However, that does not mean that adulteration did not exist.

\section{Wild-collected vs. cultivated material}

The quality of botanicals and herbal medicinal products can be linked to livelihoods of different value chains and sustainability. ${ }^{3}$ It is documented that many rural communities and indigenous groups, particularly in Asia, depend on medicinal plant collection for their livelihoods. The downside of this wild collection is as collected plants are depleted in the wild, their scarcity in the marketplace increases along with their economic value. Only an integrated chain using cultivated material may provide a better alternative to these models, but the major drawback is significant increase of price of finished product at retailer level. Due to the continuous increase of air and soil pollution, particularly in Asian countries, the level of pesticides, heavy materials and residues are predominantly presence in herbal extract. Controlled organically cultivated herbs may be the better option for cultivators. Again, organically cultivated material is typically more expensive than wild-collected material, especially when it is produced in more economically developed countries.

Due to the increasing high demand of herbal products globally, there is a pressure to find more material may lead to adulteration of the crop with similar species (e.g., as with Rhodiola species) or adulteration further down the value chain. There are also concerns by some orthodox consumers that cultivated material may be in some way inferior to wild-collected material, and subsequently the finished products are less appealing to these consumers. 


\section{Standardization}

To minimize variation in final botanical products, standardization of procedures should cover the entire field of study from cultivation of medicinal plants to clinical application. Quality control and standardization of herbal medicines involve several steps that should start with the sourcing of high quality raw material and development of criteria for precise identification of the constituents of each product, together with documentation of the role of the constituent combinations. Finally, it is necessary to establish its efficacy through biological assays and determine its adverse effect profile through literature or from toxicological studies (both short-term and long-term) followed by controlled clinical trials. ${ }^{4}$ The lack of pharmacological and clinical data on most herbal medicinal products represents a major impediment to the acceptance of natural products by conventional medicine.

\section{Seed-to-Patient Control}

Due to the inherent variability of the constituents of herbal products, it is difficult to establish quality control parameters, and batch-to-batch variation. In the absence of reference standards for identification, variability can start from the collection of raw material, and increase during storage and further processing. Generally, it is believed that the risk associated with herbal drugs is very low, but several reports on serious reactions are indicating the need for the development of safety profiles and stringent quality control systems for authentication, isolation, and standardization of herbal medicine. Reliable and consistent quality is the basis for efficacy and safety of herbal medicinal products. Proper validation of herbs used in traditional medicines needs to be done for their promotion and development.

In conducting a clinical trial, it is essential to clearly identify the plant component. The botanical identification is the first step of correct work. As a guidance tool, some experienced and tested approaches have been proposed to assist researchers in determining the quality and the safety of plant material. ${ }^{5}$

\section{Extract and finished product equivalence}

The traceability of herbal raw materials for use in herbal medicines is essential to avoid the risk of adulteration and to deliver consistent quality in products to the consumer (Anna Pohl, personal communication, 2017). The cultivation, production and primary processing of the plant/herb has a direct impact on the quality of the active components. A robust quality assurance system for the collection, harvest, storage and primary processing of the plant material is essential as a foundation to ensure consistent composition of the active compound. There are a number of Good Agricultural and Collection Practice (GACP) guidelines that should be complied with, including but not limited to:

a. American Herbal Products Association. March 2017. Good Agricultural and Collection Practices and Good Manufacturing Practices for Botanical Materials http://www.ahpa.org/ Portals/0/PDFs/Policies/Guidance-Documents/AHPA_Good Agricultural_Collection_Practices_Good_Manufacturing Practices_Botanical_Materials.pdf*

b. European Medicines Agency's Committee on Herbal Medicinal Products Guideline on Good Agricultural and Collection Practice for Starting Materials of Herbal Origin, (2006) http://www.ema.europa.eu/docs/en_GB/document_library/ Scientific_guideline/2009/09/WC500003362.pdf* c. WHO Guidelines on Good Agricultural and Collection Practices (GACP) for Medicinal Plants. (2003) http://apps. who.int/medicinedocs/pdf/s4928e/s4928e.pdf*

d. In summary, "if the plant/herb starting material is not quality controlled and therefore not equivalent, or if the extract cannot be demonstrated as equivalent, or if the finished product cannot be demonstrated as equivalent, then the evidence used to support any efficacy claims can only be matched at the level of equivalence achieved (either plant or extract or finished product level)" (Anna Pohl, personal communication, 2017).

\section{Conclusion}

Quality issues of herbal medicines can be classified into two categories: external and internal. ${ }^{6-8}$ External issues are contamination (e.g. toxic metals, pesticides residues and microbes), adulteration and misidentification, whereas complexity and non-uniformity of the ingredients in herbal medicines are the internal factors. The rigorous implementation of GACP and Good Manufacturing Practices (GMP) would undoubtedly reduce the risk of external issues. Internal issues can be managed through the use of modern analytical methods and pharmaceutical techniques.

To conclude, different concentrations of the proportion of constituents in herbal medicine may lead to great variations in therapeutic results and safety issues; consequently, the evidence for benefits and risks are specific to the product tested and cannot necessarily be extrapolated to other products, as is the case for synthetically derived compounds, and it cannot be assumed that clinical trials with one brand are relevant to any other product. Health practitioners should become more aware of these issues to recommend to their patients only the exact products that have been consistently proven to be safe and have efficacy in clinical trials conducted according to Good Clinical Practice (GCP). The gold standard of supportive evidence is certainly controlled, randomized, double-blind, clinical trials, but data from other types of studies such as case reports can improve and contribute to the primary evidence coming from more complex and controlled studies.

\section{Acknowledgements}

None.

\section{Conflict of interest}

The author declares no conflict of interest.

\section{References}

1. Fabricant DS, Farnsworth NR. The value of plants used in traditional medicine for drug discovery. Environ. Health Perspect. 2001;109(Suppl 1):69-75.

2. Cordell GA. Ecopharmacognosy and the responsibilities of natural product research to sustainability. Phytochem Lett. 2015;11:332-346.

3. Booker A, Heinrich M. Value chains of botanicals and herbal medicinal products:A European perspective. Herbalgram. 2016;112:40-45.

4. Bauer R, Tittel G. Quality assessment of herbal preparations as a precondition of pharmacological and clinical studies. Phytomedicine. 1996;2(3):193-198.

5. Zangara A, Ghosh D. Role of Seed to Patient Model in Clinically Proven Natural Medicines: Clinical aspects of functional foods and nutraceuticals. In: Ghosh D, et al. editors. Boca Raton, USA: CRC Press; 2014. p. 279-287. 
6. Zhang J, Wider B, Shang H, et al. Quality of herbal medicines:Challenges and solutions. Complement Ther Med. 2012;20(1-2):100-106.

7. Ghosh D. Seed to patient in clinically proven natural medicines: Nutraceuticals: Efficacy, safety and toxicity. Gupta RC editor. USA Elsevier/Academic Press; 2016. p. 925-931.
8. Angell M, Kassirier JP. Alternative medicine-the risks of untested and unregulated remedies. N Engl J Med. 1998;339:839-841. 